\title{
EL PAPEL DEL PRESUPUESTO \\ EN EL CRECIMIENTO ECONOMICO \\ ESPAÑOL: UNA VISION A LARGO PLAZO *
}

\author{
FRANCISCO COMIN \\ Universidad de Alcalá \\ y Fundación Empresa Pública
}

\begin{abstract}
RESUMEN
El propósito de este artículo es evaluar si la acción presupuestaria del Estado español favoreció la industrialización. En la España contemporánea los gobiernos han abusado de la reglamentación económica, mientras que no han suministrado los bienes públicos y preferentes. La frecuencia de los déficit presupuestarios y su financiación inflacionista tampoco favorecieron el crecimiento económico. Contrariamente, hasta la reforma tributaria de 1978 el régimen tributario liberal estableció una baja presión fiscal, y favoreció el ahorro, la inversión y el empleo, con el fin de impulsar la industrialización.
\end{abstract}

\begin{abstract}
This article analyzes the extent to which fiscal policy has contributed to the industrialization of Spain over the last two centuries. Spanish governments have traditionally placed excessive emphasis on policies of economic regulation but at the same time, they have failed to provide a suitable level of merit and public goods. Recurrent budget deficits were always financed by inflationary means, which did nothing to promote economic growth. In clear contrast with public expenditures, the system of taxation which prevailed until 1978, meant that there was not much of a tax burden. This allowed for a level of savings, and potential investment, which was conducive to industrialization.
\end{abstract}

\section{LA RELACION ENTRE ECONOMIA Y PRESUPUESTO: EL PUNTO DE PARTIDA}

La renta per capita española se acercó a la de los países avanzados de Europa cuando la política económica de los gobiernos permitió a este país aprovechar las influencias positivas de las coyunturas internacionales, de manera que

* Este articulo se presentó al seminario El Estado y el Crecimiento Económico en Perspectiva Histórica, del Instituto Ortega y Gasset, dirigido por Leandro Prados de la Escosura; agradezco sus comentarios, asi como los de Rafael Dobado y Juan Zafra. 
se pudieron exportar bienes, servicios y mano de obra, al tiempo que se importaban capital extranjero, bienes de equipo, productos energéticos y tecnologia exterior. Las medidas, por tanto, de los gobiernos españoles que han favorecido el crecimiento económico se definen por: 1) la política de apertura en el comercio exterior y la participación en los sistemas monetarios internacionales, así como la liberalización de los mercados interiores; 2) el control del déficit público en magnitudes pequeñas, e incluso la consecución del equilibrio presupuestario, que permitió la estabilidad monetaria y evitó las tensiones inflacionistas agudas; 3) el mantenimiento de la paz y del orden público que evitó las revueltas sociales, las revoluciones políticas y los conflictos bélicos; finalmente 4) el fomento de las infraestructuras, comunicaciones y vivienda, y los mayores gastos en educación por el Estado. El primer punto se refiere a la actividad reguladora de la actividad exterior y de los mercados internos; los otros tres tienen que ver con la política presupuestaria. Pues bien, aquí sólo me detendré a analizar con algún detalle los efectos del Presupuesto del Estado sobre el crecimiento económico ${ }^{1}$.

Los Estados que tienen una Hacienda rica y altos gastos presupuestarios favorecen el crecimiento económico, porque suministran unas funciones imprescindibles para el sector privado y la sociedad ${ }^{2}$; como la Hacienda de la España contemporánea ha sido pobre, entonces es difícil que el Estado pudiera promover el crecimiento desde el Presupuesto. Tan cierto como lo anterior, no obstante, es que la industrialización incrementa las bases recaudatorias, dotando al Estado con abundantes recursos; el atraso económico, por el contrario, mantiene Estados financieramente débiles; como España tardó en industrializarse, entonces la insuficiencia de la Hacienda fue la consecuencia histórica ${ }^{3}$. Esto significa que el Estado es un agente endógeno al proceso económico, presentándose dos direcciones de causalidad, porque la industrialización afecta a las variables presupuestarias y éstas, a su vez, impulsan o retraen el crecimiento económico. No obstante, en este artículo sólo examinaré el papel del Presupuesto del Estado en el fomento del crecimiento económico.

Como ha sucedido en Europa, también en España se ha postergado el análisis del Estado, a pesar de que para la historiografia económica ha sido una variable exógena extremadamente útil para explicar algunos acontecimientos

1 Para una visión global del papel del Estado en el crecimiento económico español, véase Comin (1993b), Prados de la Escosura (1992) y Tortella (1992).

2 Como señalaron en el seminario mencionado los profesores O'Brien, Coatsworth y Van der Wee, véanse O'Brien (1988 y 1989), Schremmer (1989), así como Davis y Huttenback (1988).

${ }_{3}$ El crecimiento del tamaño presupuestario del Estado también se ha visto retardado por el retraso político del pais; es decir, por el mantenimiento de regímenes no democráticos; véanse Fontana (1980), Comin (1985 y 1988b). 
económicos, sobre todo los fracasos industriales y las crisis económicas. La Hacienda pública es, en efecto, una institución capital para la mayor parte de las interpretaciones de la Historia económica de la España contemporánea. En un país en el que todo se espera del Estado, predominan las partidas negativas en el balance de su actuación presupuestaria frente al crecimiento y los ciclos económicos 4; a la hora de depurar las responsabilidades del atraso, lo más socorrido ha sido culpar a la política presupuestaria del Gobierno, sin detenerse a analizarla. Enunciaré brevemente las principales interpretaciones de la Historia económica española contemporánea relacionadas con el Presupuesto.

En primer lugar, en lo tocante al saldo presupuestario, es notorio que en España, a pesar del reducido gasto público, el Presupuesto del Estado se ha saldado casi siempre con déficit, porque el sistema tributario ha sido insuficiente; la idea más extendida es que esos déficit crónicos han tenido secuelas sobre la política y sobre la economia. Por un lado, los agobios de la Hacienda han condicionado la propia supervivencia de los regimenes políticos; la agonía de la Monarquía absoluta coincidió con la quiebra de la Hacienda absolutista, y la política fiscal expansiva de la Dictadura de Primo de Rivera provocó la depreciación de la peseta, que acabó minando al régimen s. Por otro lado, el déficit permanente y la deficiente gestión de la Deuda condenó a los gobiernos del siglo XIX a depender de los grandes prestamistas internacionales, que exigieron altos intereses y «compensaciones indirectas», como la legislación favorable al capital exterior, durante el Bienio progresista y el Sexenio revolucionario ${ }^{6}$. Finalmente, la financiación heterodoxa de los déficit públicos, por su monetización directa e indirecta, sometió a la política monetaria a las exigencias fiscales entre 1874 y 1983; la relajación de la disciplina monetaria desde 1883 tuvo graves repercusiones: España se alejó del patrón oro, crecieron los precios (desencadenando el impuesto inflacionista) y se depreció la divisa $?$.

4 Los historiadores quizá se han dejado influir en exceso por las críticas que los contemporáneos hacian al Presupuesto, al que se responsabilizaba de casi todos los males de la economia española.

5 Véanse las obras de Fontana (1971 y 1973), Hernandez Andreu (1980), Melguizo (1979), Palafox (1992) y Velarde (1968).

6 Véase Nadal (1975). Por su parte, Del Moral (1979) sostiene que la política fiscal expansiva con amplios déficit y el trasvase de recursos de la agricultura a la industria (a través de los impuestos y los gastos presupuestarios) favoreció el crecimiento económico español a mediados del siglo xIX.

7 Véanse Dictamen Patrón Oro (1929), Fuentes Quintana (1990) y Sardá (1948). Para Martín Aceña (1981) esa política monetaria expansiva retardó el crecimiento económico; Tortella (1981) sostiene lo contrario, pues la permisividad monetaria ahuyentó la escasez de dinero, alejando la amenaza del efecto expulsión de la inversión privada ante el aumento del gasto público, del que tanto se quejaban los empresarios españoles; sobre el efecto expulsión véanse Molinas y Prados de la Escosura (1989) y Prados de la Escosura (1993b). 
En segundo lugar, sobre las partidas del gasto, abunda la idea de que la industrialización española no se benefició de la demanda pública por la pobreza presupuestaria; además, los recortes en el gasto presupuestario sumian a la industria en profundas crisis, porque era muy dependiente de la demanda estatal. Entre las secuelas de la política de gasto público destacan: a) la franquicia a la importación de materiales para la construcción de la red ferroviaria subvencionada por el Gobierno impidió el surgimiento de una siderurgia nacional; b) los reducidos gastos públicos frenaron, asimismo, el crecimiento de una industria de transformados metálicos, concretamente de la construcción naval y de la industria armamentística; c) el origen de la crisis de los años treinta es interpretado por la reducción del gasto público del régimen republicano ${ }^{8}$; d) el insuficiente gasto militar impidió conservar las colonias americanas, relegó a España a un papel secundario en el concierto internacional y alentó el descontento del ejército; los retrasos en los sueldos provocaron los pronunciamientos del siglo XIX y las corrientes «juntistas» de principios del $\mathrm{XX}^{9}$; d) la provisión de infraestructura y de servicios preferentes (como sanidad, vivienda y educación) por el Estado español ha sido considerada insuficiente, obstaculizando el progreso de la economia ${ }^{10}$.

En la vertiente de los ingresos, en tercer lugar, siempre se ha responsabilizado a los excesivos impuestos cobrados por el Estado de originar las crisis económicas, porque encarecían los costes y retraian la iniciativa empresarial ${ }^{11}$. Contrariamente, hay quien defiende la existencia de una baja presión fiscal que impidió a los gobiernos gastar más en funciones progresivas ${ }^{12}$. Asimismo, se ha argumentado que la imposibilidad de practicar una reforma tri-

8 Véanse, para todo esto, Nadal (1975), Tortella (1981), Gómez Mendoza (1982), Suárez (1991), Palafox (1992), Hernández Andreu (1980) y Florensa (1981).

9 Véanse Carr (1980), Jover (1981), Prados de la Escosura (1988), Tedde (1981) y las colaboraciones en Prados de la Escosura y Amaral (1993).

10 Se ha argumentado que el Estado español gastó menos que otros paises europeos; y ese reducido gasto en infraestructuras (denunciado por las malas carreteras, y los insuficientes pantanos) y en capital humano (evidenciado por las pocas escuelas y maestros), con fuertes efectos externos, frenó el crecimiento económico; véanse Fuentes Quintana (1990), Vaccaro (1980), Tedde (1981) y Núñez (1990 y 1992). Aunque en los tiempos recientes han aumentado los gastos redistributivos, las deficientes infraestructuras siguen siendo un lastre para la economía española, como ha señalado Bandrés (1990a y 1990b).

11 Los ejemplos más documentados son la crisis agricola y pecuaria iniciada hacia 1882 y la crisis exportadora del textil tras la pérdida de las últimas colonias americanas (desde 1898). Para las quejas de las patronales véanse Cabrera (1983), Arana (1988) y Del Rey (1992).

12 Véase Castellano (1975), Fuentes Quintana (1990) y Tedde (1981). 
butaria forzó al Gobierno a recurrir al proteccionismo con fines recaudatorios ${ }^{13}$.

El propósito de este articulo es examinar esas hipótesis a la luz de las cifras presupuestarias del Estado liquidadas, para evaluar si la acción presupuestaria del Estado español favoreció la industrialización. Lo que está claro es que el objetivo del crecimiento económico ha sido el más antiguo y prioritario, desde los gobiernos ilustrados del siglo XVIII a la actualidad 14; otra cosa distinta es que dicho fin se haya alcanzado. En cualquier caso, hay que advertir que un proceso de crecimiento económico no es desencadenado por un solo factor, sino por un cúmulo de circunstancias; por tanto, el Presupuesto no puede explicar por si solo las fases de crecimiento ni el atraso económico español. Otras acciones públicas fueron más significativas que la política presupuestaria: por ejemplo, la cerrada protección arancelaria y la regulación de los mercados crearon un contexto legal que influyó poderosamente sobre el atraso económico del país; además, si el Estado no impulsó desde el Presupuesto adecuadamente el crecimiento económico, el papel de los empresarios nacionales, tanto del sector real como del financiero, no destacó por su brillantez ${ }^{15}$.

La clave de la cuestión está en que durante la España contemporánea, la pobreza de la Hacienda indujo al Estado a apoyar a la economia mediante leyes y decretos que regulaban la actividad de las empresas y los mercados, siempre que no incrementasen los gastos del Presupuesto. Como en muchos paises atrasados, los gobiernos españoles sustituyeron y tutelaron los mercados, pero no realizaron las funciones claves para corregir sus deficiencias; consecuentemente, aquellas intervenciones públicas mediante los precios tasados, las licencias, los cupos y el corporativismo productivo, así como la financiación inflacionista acabaron distorsionando los mercados, impidiendo su eficiencia. En la España contemporánea los gobiernos han abusado de la reglamentación de la actividad económica, encaminada a sustituir al mercado, mientras que han descuidado la provisión de los bienes públicos y preferentes que favorecen el crecimiento económico ${ }^{16}$.

13 Según la opinión de Lluch (1988); Serrano Sanz (1991), empero, sostiene lo contrario.

14 Los ilustrados ya proponian remover los obstáculos institucionales al crecimiento y gastar en infraestructuras y educación; véanse Fuentes Quintana (1991) y Llombart (1992).

15 Recuérdese que la defectuosa política arancelaria, que impedia que algún sector alcanzase alguna ventaja comparativa, fue impuesta por las organizaciones patronales, al menos hasta la Guerra Civil; véanse Fraile (1985 y 1991), Serrano Sanz (1987a y 1989) y Sabaté (1992).

it La regulación es un instrumento útil para corregir las imperfecciones del mercado, me- 
A continuación me ocupare de las influencias sobre el crecimiento económico, primero, del déficit público, después de los gastos, y finalmente de los ingresos públicos.

\section{EL DEFICIT PUBLICO CRONICO: UN IMPULSO INSUFICIENTE}

Los déficit públicos prevalecieron en la España contemporánea, si se exceptúan los períodos 1899-1908 y 1951-1975 (gráfico 1) ${ }^{17}$, indicando que, desde una perspectiva keynesiana, la política fiscal ha sido, casi siempre, expansiva y favorable al crecimiento económico, sobre todo si se tiene en cuenta que el déficit fue acompañado permanentemente por una política monetaria permisiva ${ }^{18}$. Desde la escuela clásica, por el contrario, se diría que los déficit del Estado retrajeron el crecimiento económico, porque su financiación expulsó parcialmente a la inversión privada, al aumentar los tipos de interés. Ambas interpretaciones pueden aplicarse a distintas épocas, porque no hay una relación clara entre los déficit del Estado y el crecimiento económico español entre 1850 y 1990 (gráfico 2 ) ${ }^{19}$.

diante la legislación antimonopolios, de accidentes de trabajo, de defensa del consumidor; pero las leyes económicas de este pais fueron en dirección opuesta, pues legalizaron esas imperfecciones mediante un proteccionismo integral, el corporativismo que sancionó oficialmente los oligopolios y las reglamentaciones que pretendian «disciplinar el mercadom; véanse Fuentes Quintana (1989 y 1993), García Delgado (1987), Palafox (1992), Segura (1992) y Serrano Sanz (1986, 1987a y $1987 b)$.

17 Con respecto a las fuentes de los gráficos de este articulo, las cifras reales proceden de Prados de la Escosura (1993a) - a quien agradezco que me haya dejado utilizarlas antes de su publicación-, de Corrales y Taguas (1991) y del INE (1993); las del sector püblico son de Co$\min (1993 a)$.

18 Desde 1883 cuando, una vez concedido el monopolio de emisión al Banco de España, se declaró la no convertibilidad de la divisa, no se conocieron estrecheces monetarias; se abandonaron los tipos de cambio fijos de los patrones metalicos, y, por tanto, dejó de existir una política monetaria autónoma; la circulación fiduciaria se subordinó a la financiación de los déficit presupuestarios, lo que aseguró un mayor efecto multiplicador del gasto público. El control de cambios practicado con intermitencias de 1929 a 1935 fue ineficaz; y la paridad oficial fija posterior a 1939 no implicó ningún tipo de restricción monetaria hasta 1958. Sólo desde 1983 se ha vuelto a practicar una politica ortodoxa de financiación del déficit, y la politica fiscal expansiva se ha compaginado con una política monetaria restrictiva.

19 En el gráfico 2 se advierte que la tasa de crecimiento del PIB aumenta con el déficit, pero la recta de regresión entre crecimiento y saldo presupuestario presenta un ajuste muy malo a la nube de puntos. Esto indica que habia otras variables que influian más que el déficit presupuestario sobre la evolución de la economia real. 


\section{GRAFICO 1}

Porcentaje en el PIB (1850-1990)

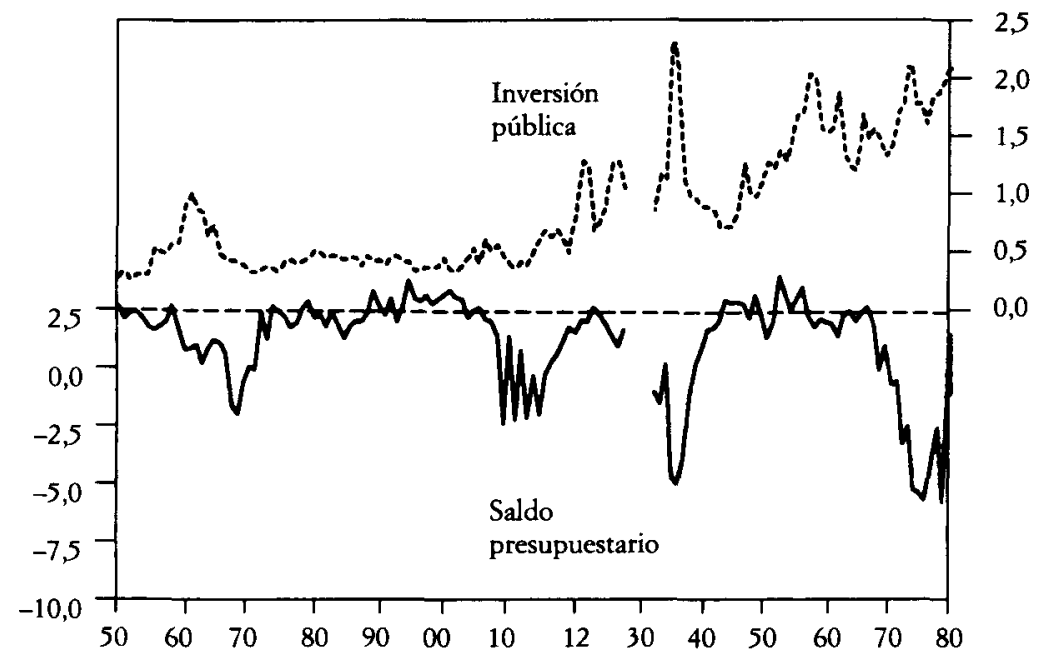

\section{GRAFICO 2}

Tasa de crecimiento del PIB y saldo presupuestario/PIB (1850-1990)

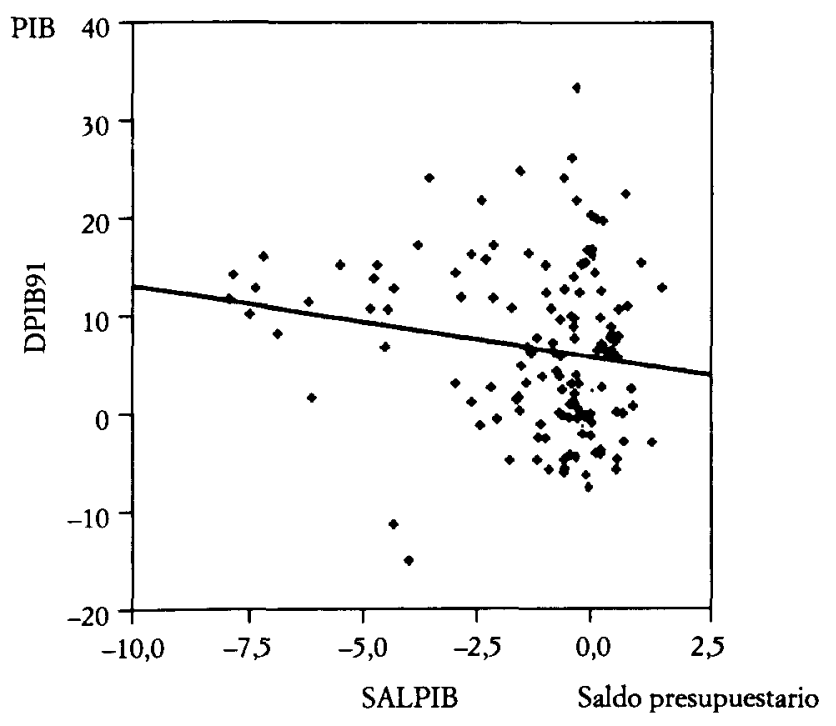


Para ilustrar lo anterior examinaré la relación entre déficit y crecimiento en los períodos con mayores insuficiencias presupuestarias, que fueron 1870 $1874,1915.1919,1940-1949$ y 1977-1986. Pues bien, mientras que en el Sexenio democrático el crecimiento económico fue apreciable, durante la Primera Guerra Mundial la economia española permaneció estancada ${ }^{20}$; por otro lado, en el primer franquismo y en la transición a la democracia se experimentaron las crisis más profundas de la economía española en el siglo xx. Los déficit del Estado coincidieron preferentemente con depresiones económicas; la razón fue que los déficit eran, en una parte considerable, coyunturales, por la caída de ingresos y el aumento del gasto ocasionados por las caidas en la actividad económica. Antes de 1977, los impuestos y los gastos públicos no eran muy elásticos a la coyuntura económica, porque los déficit coyunturales no tenian gran amplitud 21 .

Más que en los déficit públicos las causas del crecimiento del Sexenio se encuentran en las medidas de Laureano Figuerola, que liberalizaron las fuerzas del mercado, exterior e interior ${ }^{22}$. Durante los años de la Primera Guerra Mundial, la inversión privada descendió por la excepcional coyuntura bélica, y no porque fuese expulsada por el déficit público ${ }^{23}$. En el gráfico 3 se advierte que no hay ninguna relación significativa entre el déficit público y la inversión total de la economia. Por su parte, la profunda crisis económica de los cuarenta tuvo sus raíces más en la política autárquica, en los precios administrados y en el ordenancismo de la producción, que en los déficit del Presupuesto, que

${ }^{20}$ Las estimaciones más recientes señalan que el auge del que tradicionalmente se ha hablado no existió a nivel agregado; véase Carreras (1992) y Sudrià (1990).

${ }^{21}$ Analizando el impuesto que más reaccionaba ante el ciclo económico, que era la renta de Aduanas, se advierte que después de la reforma de Figuerola, su recaudación aumentó. En el Sexenio los determinantes en el surgimiento del déficit fueron: a) las cargas financieras surgidas de los déficit de los años 1860 , generados en parte por la crisis económica de aquella década; b) la abolición de la Contribución de consumos, que hizo descender la recaudación. Por el contrario, durante los años 1915-1919, 1931-1933 y 1940-1957 la disminución de los rendimientos del Arancel de Aduanas fue responsable parcial del déficit presupuestario; la recuperación de los rendimientos del impuesto sobre el comercio exterior en los años siguientes explica algo la disminución del déficit público; véanse Costas Comesaña (1988) y Carreras (1990).

22 Particularmente, el arancel Figuerola, la liberalización de los mercados interiores y ladesamortización del subsuelo que facilitó el auge minero promovido por la inversión exterior, que creció entre 1869 y 1874 ; es más, en este periodo los déficit públicos se financiaron parcial. mente con Deuda exterior, lo que desahogó los mercados financieros del interior. Véanse Costas Comesaña (1988) y Martín Niño (1972).

${ }^{23}$ En la caída de la formación de capital fijo influyeron: a) la incertidumbre de los tiempos; b) el capital se destinó a negocios especulativos y no a la inversión productiva; c) la exportación de capital; d) la inversión en capital circulante y en existencias; e) la dificultad de importar maquinaria, $y$ f) los mayores costes generales y laborales de las empresas españolas; véanse Carreras (1990), Comin (1988a), Garcia Delgado (1984), Maluquer de Motes (1987), Sudrià (1990). 
sólo fueron grandes mientras se pagaron los atrasos de guerra ${ }^{24}$. A su vez, la crisis de los setenta se originó en el exterior, aunque su repercusión en España fue agudizada por la deficiente estructura industrial española (especializada en los sectores de demanda débil, que fueron los más golpeados por la crisis, y muy dependiente del exterior en productos energéticos), y porque la política económica tardó demasiado en reaccionar ante la crisis. Que los déficit püblicos eran resultado de las depresiones económicas es muy claro en esta fase de 1977-1986, cuando se ha comprobado que gran parte del déficit era coyuntural, es decir, originado por la propia crisis, que redujo la recaudación por el Impuesto sobre la renta de las personas físicas y los impuestos indirectos, y aumentó los gastos, por el seguro de desempleo, jubilaciones adelantadas y subvenciones de explotación a las empresas 25.

En el período de entreguerras, el déficit presupuestario no generó los ciclos económicos porque en términos relativos era pequeño; menor que durante el Sexenio democrático y la Primera Guerra Mundial. En los años veinte, los déficit del Estado no retrajeron la inversión privada, pues ésta aumentó y hubo crecimiento económico; en los treinta, los déficit públicos fueron acompañados por un descenso en la inversión privada y hubo una crisis económica global, aunque menos grave que en otros países europeos. En el comportamiento diferencial de la economía española de los años años veinte y treinta influyeron más otras causas que el Presupuesto del Estado 26

Es complicado, por tanto, comprobar empíricamente si los déficit del Estado impulsaron o retardaron el crecimiento de la economía española; en cualquier caso, no es probable que el déficit público expulsase la inversión privada (gráfico 3); aunque no hay que descartar que, en ocasiones, la desplazase parcialmente ya que encarecía su financiación ${ }^{27}$. Hay motivos, en cualquier

24 Véanse Garcia Delgado (1987), Comin (1986), Martin Aceña y Comín (1991) y Catalán (1992).

25 Asimismo, el descenso del déficit público posterior a 1986 tuvo su origen en la recuperación económica y en la implantación del IVA. En esa recuperación posterior a 1985 influyeron otros factores como la reconversión industrial y el auge internacional. Los estabilizadores automáticos y la recuperación económica redujeron el déficit coyuntural, permaneciendo el déficit estructural (es decir aquel decidido por la estructura de ingresos y gastos del gobierno) que es el que aparece cuando la economia alcanza el pleno empleo.

26 Como las siguientes: a) la distinta coyuntura exterior, de crecimiento en los veinte y de recesión en los treinta; b) las buenas expectativas empresariales durante la Dictadura de Primo de Rivera y su ensombrecimiento ante los cambios politicos posteriores, y c) las reformas laborales $e$ institucionales de la Segunda República; véase Comin (1987a y 1988a).

27 Hay que tener presente, sin embargo, que no es suficiente con establecer una relación empírica entre déficit y aumento del tipo de interés para hablar de crowding out, además, hay que demostrar que el incremento del tipo de interés determina una caida de la inversión; esta última causalidad no está confirmada empiricamente, pues el aumento del interés no siempre expulsa a 
caso, que descartan la presencia generalizada de un efecto expulsión de la inversión privada en la España contemporánea a causa del déficit ${ }^{28}$ : en primer lugar, a la oferta interior de fondos prestables hay que añadir las considerables inversiones de capital exterior, pues la importación de capital ha sido frecuente y ha coincidido con los períodos de crecimiento económico; en segundo lugar, en pocas ocasiones ha existido pleno empleo de los factores productivos, ni del trabajo ni del capital; un problema secular en España han sido el desempleo y subempleo de los factores de producción; en tercer lugar, el Estado no podía acaparar todos los fondos ahorrados, pues el déficit público era pequeño en relación con los activos financieros de la economía; por pequeña que fuese, es improbable que la tasa de ahorro no superase al déficit, salvo en las fases excepcionales; el problema financiero surgía menos de una insuficiencia de ahorro, que del atraso de los intermediarios financieros, que no convertían el ahorro en saldos prestables ${ }^{29}$; en cuarto lugar, más bien parece que la necesidad de financiación del Estado absorbía recursos que no tenían otra ocupación, permitiendo a los bancos obtener una rentabilidad; en efecto, los bancos mantenían ociosos sus recursos, por la escasa demanda de crédito, pues las empresas españolas se autofinanciaban en gran medida; en quinto lugar, rara vez los déficit presupuestarios fueron acompañados por restricciones monetarias; en situaciones con déficit presupuestario sólo hubo disciplina monetaria antes de 1883 y después de 1983.

la inversión privada, ya que existen otros factores determinantes de la inversión como las politicas extrapresupuestarias de los Gobiernos, la inversión exterior, las expectativas empresariales, los stocks de producto acumulados, la capacidad instalada, la demanda privada esperada y, en fin, grado de desarrollo de los mercados financieros.

28 Para evaluar propiamente la presencia del efecto expulsión habria que considerar las siguientes cuestiones: a) la existencia de pleno empleo; b) cómo era la política monetaria, y c) si habia inversiones extranjeras. Habria que comprobar, en suma, si en la economia española contemporánea se cumplian los supuestos que subyacen a la teoria clásica, o si, por el contrario, la infrautilización de los recursos humanos y de capital hacia que los déficit del Estado, aunque no fuesen buscados, no tuvieran las perniciosas secuelas que la escuela clásica pregonaba; de cumplirse estos supuestos keynesianos, los saldos negativos pudieron tener efectos favorables sobre la economía. Pero no hay cifras suficientes para hacer las estimaciones econométricas, y aunque las hubiera, tampoco se alcanzarian resultados concluyentes, como sucede con los estudios sobre la actualidad, ya que los procedimientos econométricos más rigurosos tampoco consiguen el acuerdo sobre la presencia del efecto expulsión en tiempos recientes; véanse Mora (1984), Raymond (1992) y Argimón y Roldán (1991).

29 En efecto, antes de 1975, el tamaño del déficit presupuestario era pequeño, salvo en ciertos periodos, en comparación a la renta nacional, con lo que sus efectos expansivos no podian ser muy grandes, y frente al volumen de fondos prestables, por lo que no podia presionar sobre los mercados de capitales, por estrechos que éstos fuesen. Cuando el déficit se financiaba movilizando ahorro, como ocurrió con la Caja General de Depósitos entre 1853 y 1868, tampoco hubo crowding out, véanse Gonzalo (1981), Tedde (1985) y Martín Aceña (1985). 


\section{GRAFICO 3}

Inversión total y saldo presupuestario (porcentaje del PIB) (1850-1990)

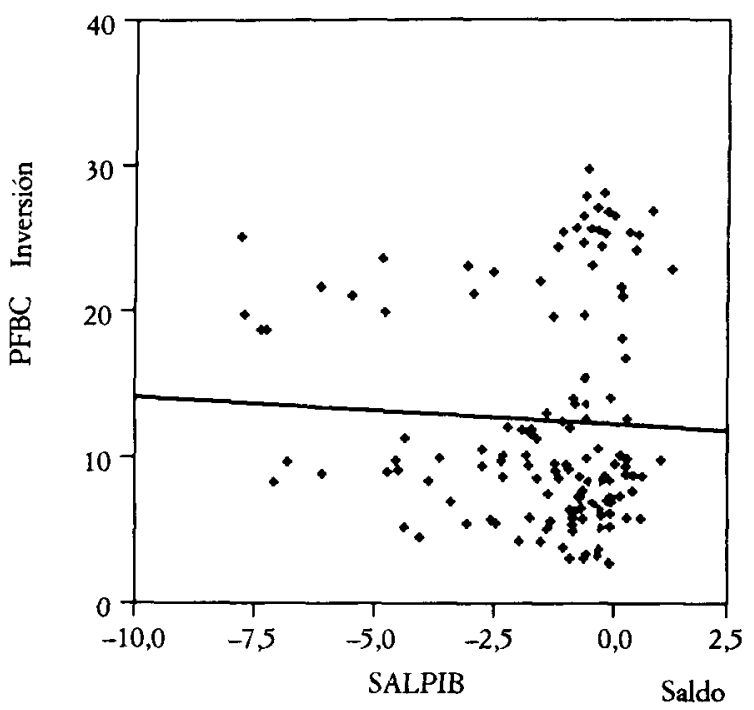

\section{GRAFICO 4}

Tasa de inflación y saldo presupuestario/PIB (1850-1990)

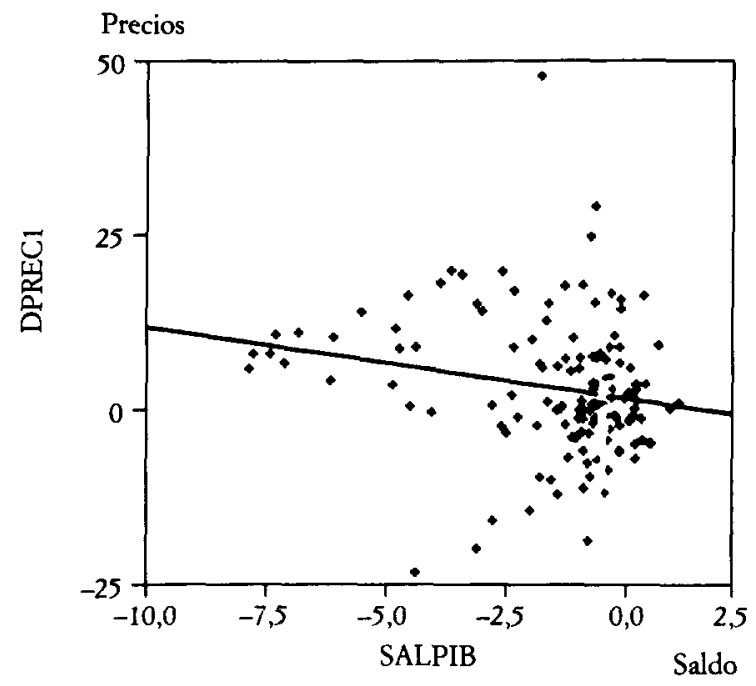


La financiación del déficit público era potencialmente muy inflacionista, porque se podia monetizar directamente el déficit, como en 1883-1917 y en 1977-1982, o bien se abría la puerta para monetizarlo indirectamente, como cuando el déficit se financió con Deuda, cuyas emisiones entre 1917 y 1957 eran pignorables; ello descartaba situaciones de tirantez monetaria que están en la base del efecto expulsión, pero sembraba el peligro inflacionista ${ }^{30}$. La ausencia de pleno empleo en la historia contemporánea de España (salvo en la década de 1960, gracias al crecimiento económico y a la emigración a Europa), ayuda a explicar que los efectos inflacionistas de los déficit del Estado no fuesen preocupantes, si exceptuamos los periodos 1915-1920, 1940-1959 y 1975 . 1983; el gráfico 4 muestra que cuanto mayor fuese el déficit más alta era la tasa de inflación; no obstante, la relación es muy débil y el ajuste muy deficiente ${ }^{31}$.

Aunque los efectos directos del déficit sobre el crecimiento económico fueron débiles, las insuficiencias de la Hacienda pública tuvieron graves secuelas indirectas, pues contribuyeron a distorsionar la asignación de recursos en la España contemporánea: primero fue a través de la regulación económica objeto de las «compensaciones indirectas» $y$, después, mediante la financiación inflacionista del déficit público. Los compensaciones indirectas que el Estado concedió a sus prestamistas consistieron en una legislación arbitrariamente favorable a ciertos sectores económicos y a determinadas compañias extranjeras y nacionales ${ }^{32}$. Desde 1874 con el monopolio de emisión al Banco de España y sobre todo tras 1883 , cuando se declaró la inconvertibilidad en oro de los billetes españoles, la moneda fiduciaria adquirió carta de naturaleza en España. El recurso directo e indirecto del Tesoro al Banco de España dejó a la política monetaria sin autonomía, sometiéndola a las necesidades de financiación del Presupuesto, lo que ampliaba la oferta monetaria ${ }^{33}$. Está probado que en los períodos con inflación el crecimiento económico español se vio frenado.

${ }^{30}$ Los efectos inflacionistas fueron moderados porque la mayor parte de la Deuda pública quedaba en la cartera de los bancos sin pignorar, lo que es un indicio más de la insuficiente demanda privada de crédito; véase Martín Aceña (1984).

${ }^{31}$ Esa financiación a través de la Deuda pública hizo, en cualquier caso, que los efectos de los déficit sobre la expansión económica fuesen inferiores a los que se hubiesen experimentado si la financiación se hubiese realizado con recursos al Banco de España o que si toda la Deuda pignorable se hubiese pignorado; véanse Comin (1987b) y Solé Villalonga (1964).

32 Destacan las siguientes medidas: Ley de Bancos de emisión y Ley Ferroviaria del Bienio progresista; Ley minera del Sexenio; la concesión del monopolio de emisión de cédulas hipotecarias al Banco Hipotecario en 1872 y de billetes al Banco de Espana en 1874. Para los nefastos efectos de la legislación progresista sobre la industrialización española, véase Nadal (1975); el monopolio del Banco Hipotecario «hipotecóm, nunca mejor dicho, el desarrollo del crédito agra. rio en este pais.

33 En la medida que el déficit obligaba al Tesoro a acudir al Banco de España o a emitir Deuda pignorable. Los efectos del saldo presupuestario sobre la oferta monetaria implicaban pér- 
En definitiva, poco puede decirse a nivel general sobre la relación entre el déficit público y el crecimiento, porque los efectos del déficit dependen no sólo de cómo se financie, sino de cuáles sean los gastos que lo originen.

\section{EL GASTO PUBLICO: \\ UN OBSTACULO AL CRECIMIENTO}

En la España contemporánea los gastos públicos no favorecieron el crecimiento económico hasta tiempos muy recientes, porque eran pequeños en relación al PIB (gráfico 5) y porque, además, estaban mal distribuidos, pues la mayor parte se destinaba a satisfacer los intereses de los préstamos, a mantener las tropas y a pagar a los funcionarios; cuando el gasto público amplió su dimensión desde mediados de los años 1960, tampoco apoyó claramente al crecimiento económico, porque más de la mitad se destinaba a transferencias, mientras que la inversión pública era reducida y se gastaba poco en educación y sanidad. De manera que, antes de los sesenta, el Estado no construyó una red viaria ni una infraestructura hidráulica adecuadas para el desarrollo económico del país; tampoco contribuyó a crear un capital humano imprescindible para la industrialización; todavia en la actualidad el capital social público sigue siendo insuficiente. Este generalizado juicio tan negativo sobre el papel del gasto público en el crecimiento económico es incuestionable, pero requiere alguna matización.

En primer lugar, se tiende a pasar por alto que el Estado liberal dedicó más atención al crecimiento económico; en efecto, después de 1845, los gastos en servicios económicos de la Hacienda aumentaron en relación a los del Estado absoluto ${ }^{34}$. En segundo lugar, los gastos en infraestructura del sector público español entre 1850 y 1958 están infravalorados, porque algunos fondos públicos dedicados a la educación, construcción de ferrocarriles, carreteras, caminos y puertos no están incluidos en las liquidaciones presupuestarias del Estado ${ }^{35}$. En tercer lugar, se olvida que ciertos gobiernos industrialistas im-

\footnotetext{
didas y ganancias de flujos, de tal manera que la variación anual de la oferta monetaria tenia cuantitativamente poco que ver con la dimensión del déficit presupuestario del Estado del ejercicio, pues, como señaló Martín Aceña (1985b), habia otros determinantes de las variables monetarias.

34 Creció el volumen de gasto público y la ideologia liberal transformó la estructura del gasto de la Hacienda Real del Antiguo Régimen, para encomendar al Estado el suministro de los bienes públicos y el fomento del crecimiento económico; véase Comín (1991a).

35 Muchas ayudas públicas para el fomento de la actividad privada se hicieron pagándolas directamente con títulos de la Deuda pública y mediante gastos fiscales, que no se incluian en
} 
pulsaron los gastos económicos en períodos como 1856-1863, 1926-1935, $1965-1975$ y $1982-1992{ }^{36}$. El problema, con todo, no era tanto el nivel de gasto, sino su deficiente gestión y su escasa eficacia social ${ }^{37}$; por ejemplo, la construcción de la red ferroviaria a mediados del siglo XIX, que fue subvencionada con fondos públicos, ha sido criticada por ser excesivamente rápida, poco meditada y no muy conveniente para la economía del pais, por lo que tuvo escasos efectos multiplicadores en el interior ${ }^{38}$.

En cuarto lugar, la provisión de bienes y servicios públicos por el Estado no depende tanto de que los gobernantes quieran ofrecerlos, como de su demanda social que, a su vez, es función del progreso económico y social alcanzado por el país y del régimen político vigente. Los gobiernos de otros países europeos gastaban más, especialmente en servicios económicos y sociales, que los de España ${ }^{39}$, porque esas naciones estaban más desarrolladas económica, social y políticamente ${ }^{40}$. Es decir, que dados el atraso de la economía, el escaso progreso social y la imperfecta democracia política de la España del siglo XIX, es lógico que el Estado ofreciese menos servicios económicos y sociales. Desde finales del siglo XIX hubo sufragio universal masculino y la economía española se desarrolló hasta 1935; paralelamente, el Estado empezó a gastar más en los servicios económicos y en educación; con los cambios de régimen en los veinte y los treinta, el tamaño relativo del Estado se amplió, particularmente en los gastos económicos y sociales. Pero el franquismo autárquico retrasó la

los Presupuestos; asimismo, las cifras que he podido manejar muestran que que no pueden despreciarse los gastos municipales y provinciales en funciones como educación, sanidad y caminos, ni los desembolsos de los organismos autónomos, particularmente en obras de infraestructura; véanse Comin (1988), Antolin (1991) y Núñez (1992).

36 Como se advierte en el gráfico 1, ese aumento de la inversión explica en parte el mayor déficit presupuestario en esas fases, salvo en la correspondiente a 1965-1975; y se sabe que ese déficit favorece el crecimiento económico, porque los Estados pueden endeudarse para invertir, como hacen las empresas privadas.

37 A pesar de las leyes de contabilidad, el trasvase de fondos de unas partidas presupuestarias a otras era normal, y la utilización de los fondos públicos no siempre llegaba a sus destinos. Por no hablar de la corrupción funcionarial y politica en la gestión del gasto, sobre la que hay ejemplos en Comín (1988a) y Varela (1977).

${ }_{38}$ Véanse Nadal (1975) y Comin (1988a). La construcción de autopistas - también en régimen de concesión - desde los años sesenta tambien tuvo un coste excesivo para el Estado, a través de los seguros de cambio, para el beneficio social reportado. Las inversiones en las compañias tecnológicas de Telefónica o la construcción por RENFE del ferrocarril de alta velocidad Madrid-Sevilla, también han sido cuestionadas; sobre todo por el coste de oportunidad del dinero público empleado en esos proyectos; véase Gómez Mendoza (1989).

39 Véase Tedde (1981).

40 En ellas, la demanda de gasto público era mayor y habian permitido modernizar sus sistemas tributarios, lo que - además de proporcionar los imprescindibles recursos para financiar los recién nacidos gastos- anunciaba una nueva concepción de la equidad impositiva y que sus gobiernos se habian comprometido con funciones progresivas del gasto. 


\section{GRAFICO 5}

Gasto público/PIB (porcentajes) (1850-1990)

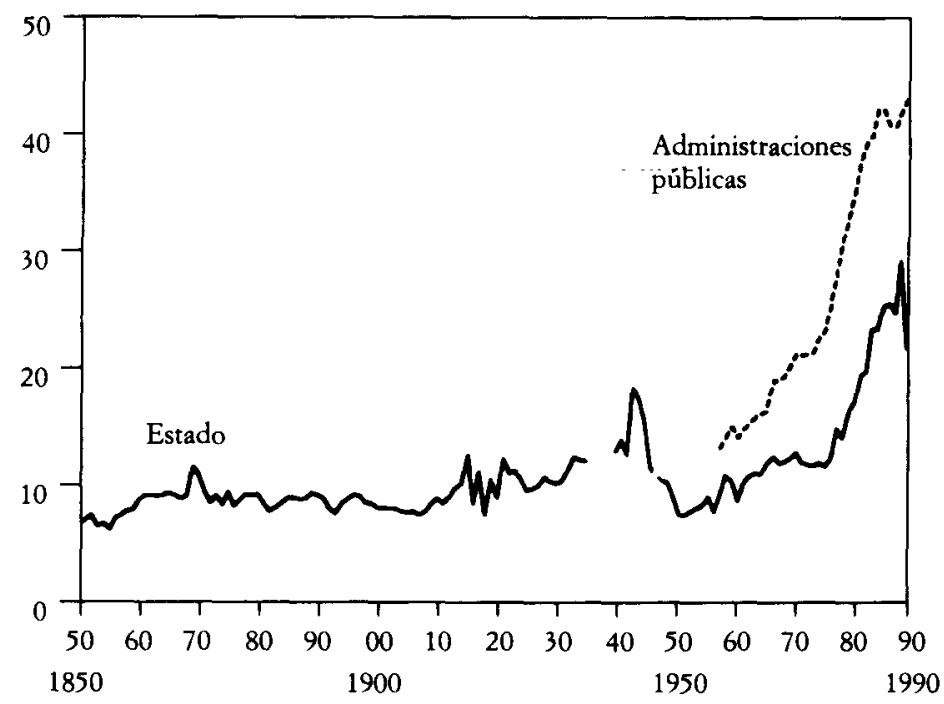

\section{GRAFICO 6}

Tasa de crecimiento y gasto príblico/PIB (1850-1990)

Crecimiento

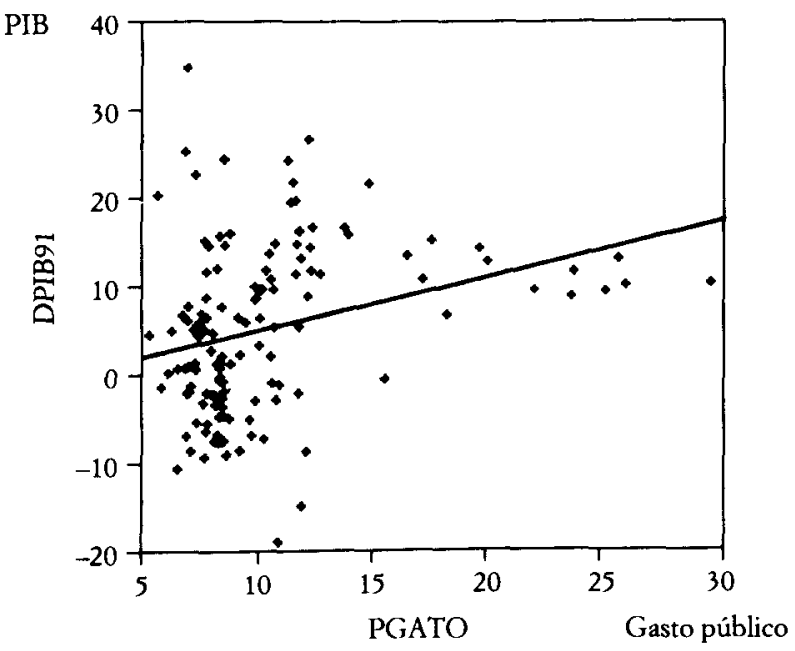




\section{GRAFICO 7}

Porcentaje frente al gasto del Estado (1850-1990)

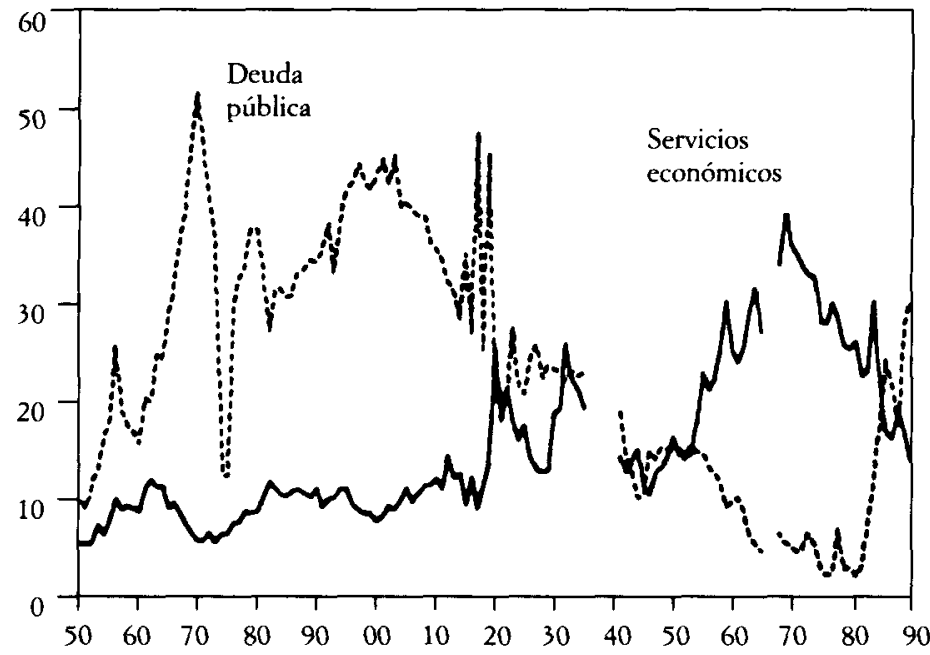

GRAFICO 8

Porcentaje frente al gasto del Estado (1850-1990)

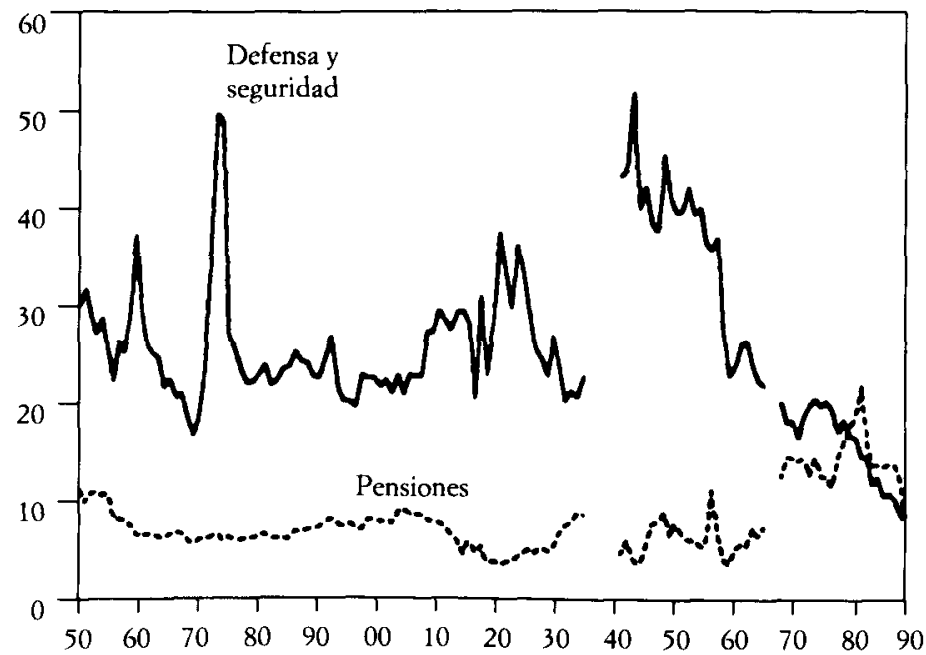


modernización del gasto público en España, y su dimensión siguió siendo muy pequeña hasta mediados de los años 1970 (gráfico 5).

Consecuentemente, las repercusiones del gasto público sobre el crecimiento económico no podian ser notables; en el gráfico 6 se aprecia una débil relación entre el gasto público y la tasa de crecimiento PIB. El análisis de la estructura del gasto público confirma el poco apoyo que el gasto público proporcionó al crecimiento. En efecto, como se aprecia en los gráficos 7 y 8 , antes de 1966, el grueso del gasto de las Administraciones Públicas se destinaba a tres funciones: Intereses de la Deuda, Defensa y Servicios generales; con lo que apenas quedaban fondos para las atenciones económicas y los gastos sociales, como las obras de infraestructura, la educación, la vivienda, la sanidad o las transferencias de renta. Esto indica que desde la clasificación económica del gasto, el dinero destinado a inversión pública no fue mucho, lo que fue una pena, pues el gráfico 9 sugiere una relación positiva entre la inversión pública y el crecimiento del PIB.

Llama la atención, no obstante, que historiadores y hacendistas no hayan estudiado los gastos públicos en justicia, policía y defensa, con el mismo interés dedicado a los gastos económicos. Aquellos gastos en bienes públicos puros eran los realmente decisivos, en el modelo liberal y clásico, para favorecer el crecimiento económico, pues de ellos dependia la seguridad de la propiedad privada y los contratos comerciales, el buen funcionamiento del mercado y la libertad de la iniciativa empresarial, que eran las claves del crecimiento económico. Pues bien, parece evidente que el Estado español mantuvo indotadas esas funciones, particularmente la justicia y la defensa exterior; la inseguridad jurídica, la pérdida de las colonias americanas (y la incapacidad colonial en Africa), asi como también la excesiva duración de las guerras, todo ello derivado de los insuficientes gastos en justicia y en defensa, acabaron obstruyendo el crecimiento económico en España ${ }^{41}$.

Sólo desde los años sesenta el gasto de las Administraciones públicas recuperó la tendencia a la modernización, perdida en la autarquía, aumentando el volumen presupuestario y dedicando más dinero público a la inversión social tangible y en capital humano, asi como a la seguridad social. Pero en los años sesenta el gasto público tampoco impulsó el crecimiento económico; su acción fue muy insuficiente, pues creció menos de lo necesario, y en términos relativos las inversiones acabaron disminuyendo. El notable aumento del Presupuesto de las Administraciones públicas desde 1976 no se destinó a la inver-

11 Estas funciones del Estado fueron basicas en la industrialización del Reino Unido y de sus colonias, como señalaron Davis y Huttenback (1988), O’Brien (1988) y Schremmer (1989). 


\section{GRAFICO 9}

Tasa de crecimiento e inversión pública/PIB (1850-1990)

Tasa incremento

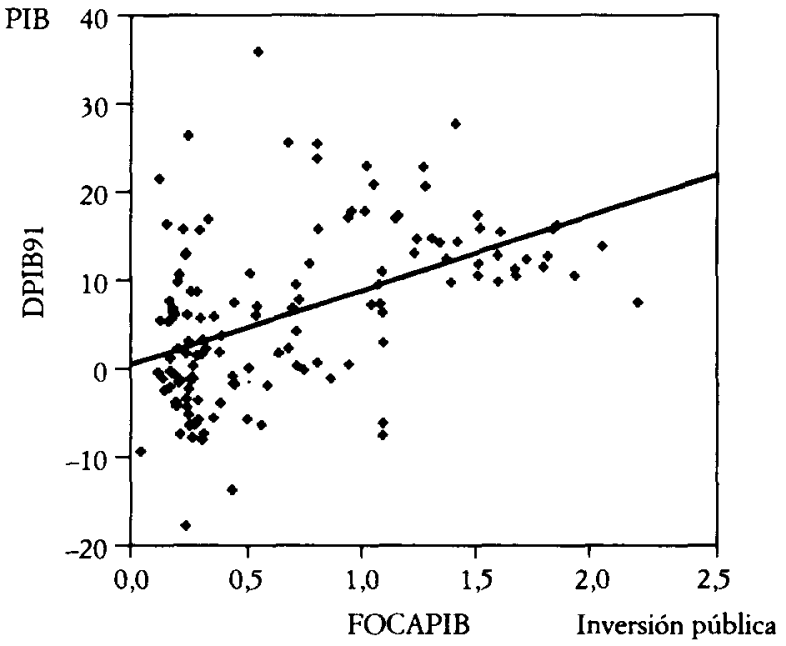

GRAFICO 10

Tasa de crecimiento y presión fiscal (1850-1990)

Crecimiento

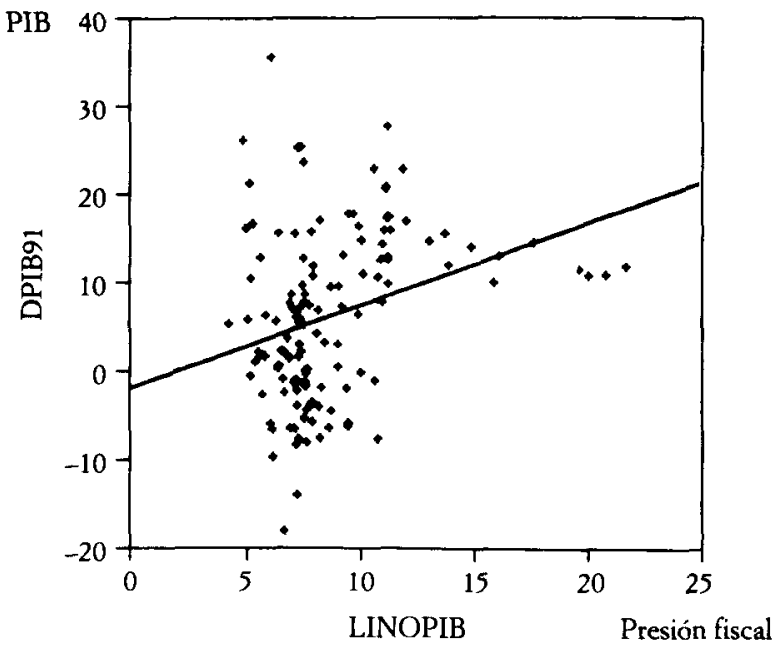


sión pública, sino preferentemetne a transferencias a las familias, a las empresas y a los tenedores de la Deuda pública; lo que prolongó la tendencia al deterioro de las infraestructuras públicas, colapsando el crecimiento económico. Aunque desde 1977 han mejorado los gastos en educación y sanidad, su cobertura sigue siendo insuficiente - y deficiente su calidad- para las demandas sociales y las necesidades de la economía. Todo ello ha llevado a una estructura del gasto más preocupada por la redistribución que por el crecimiento, pues las energías del Presupuesto se destinan a redistribuir la renta y suministrar bienes preferentes ${ }^{42}$.

Conviene resaltar, empero, que la exigua dimensión del gasto público y su atrasada estructura hasta los tiempos actuales no era algo casual ni indicaba despreocupación de los gobiernos, sino que era algo deliberado hasta mediados de la década de 1960, cuando predominó la ideología liberal ${ }^{43}$. Esto era así, porque la ortodoxia financiera liberal no propugnaba una política beligerante de gasto público, salvo en lo que a infraestructuras se refiere, porque confiaba en la política impositiva para fomentar el crecimiento económico.

\section{UN SISTEMA FISCAL FAVORABLE AL CRECIMIENTO}

La reforma de 1845 , obra de los moderados Mon-Santillán, instauró el régimen tributario liberal que estableció una débil presión fiscal con el propósito de impulsar el crecimiento económico ${ }^{44}$. La Hacienda liberal del siglo XIX buscaba esencialmente el objetivo del crecimiento económico, algo imposible de alcanzar con el cuadro tributario del Antiguo Régimen, que era insuficiente y ponia trabas a la producción y la circulación de los productos, como denunciaron los ilustrados en la segunda mitad del siglo xviI. Las reformas impositivas y arancelarias de los años 1840 desgravaron el ahorro, la inversión y el trabajo asalariado y rebajaron las trabas al comercio interior y exterior ${ }^{45}$.

42 La especialización redistributiva del Estado benefactor, además de restar fondos para la inversión pública, ha podido impedir que el Estado suministre adecuadamente los bienes públicos puros, como revelan el deterioro de la seguridad ciudadana y el lento funcionamiento de la justicia. Véase Fuentes Quintana (1993) y Bandrés (1990).

${ }^{43}$ Mantenida por los ministros de Hacienda en España hasta mediados de los años sesenta; véanse las memorias de Navarro Rubio (1992).

44 En contrapartida, era un sistema fiscal discriminatorio, por sectores y grupos sociales, que impedia la equidad y que distorsionaba la asignación de recursos. Para las reformas de 1945 y 1900, véanse Estape (1971), Fuentes Quintana (1990), Comin (1988a) y Solé Villalonga (1967).

${ }^{45} \mathrm{La}$ reforma de la década moderada apartó los obstáculos puestos al crecimiento por la $\mathrm{Ha}$ cienda del Antiguo Régimen, aunque sólo fuera por la desaparición de Aduanas interiores, del 
En primer lugar, la imposición indirecta en la fiscalidad liberal recaía sobre los articulos más consumidos por las rentas bajas, con mayor propensión al consumo; al contrario que la Alcabala, los inputs productivos elaborados en el mercado interior quedaron exentos: también se gravaban los productos que pasaban las Aduanas exteriores, cuyos aranceles eran más protectores que fiscales, si se exceptúan algunos productos coloniales ${ }^{46}$. En segundo lugar, los impuestos de producto no permitían la progresividad, ni gravaban la renta de las personas -ni físicas, ni jurídicas-; además, sólo muy tardiamente se fiscalizaron con alguna intensidad los rendimientos del trabajo, del capital y los beneficios de las sociedades ${ }^{47}$. En tercer lugar, desde 1845 , la tributación directa recayó más duramente sobre la agricultura que sobre la industria y el comercio, y se generó una mayor presión fiscal sobre los ingresos de los campesinos que sobre la renta de los terratenientes. Así pues, la reforma de 1845 no fiscalizó el ahorro de los grupos con mayor propensión al mismo, y los procesos de producción quedaban exentos con un saludable efecto sobre los costes 48 .

Desde la reforma de Fernández Villaverde en 1900, las rentas de capital y las actividades industriales y comerciales se gravaron algo más; no obstante, la inexistencia de un impuesto sobre la renta y el predominio de la imposición indirecta, sobre todo cuando se incluyen en la misma los monopolios del Estado, todavía configuraban un sistema tributario favorable al crecimiento económico. La presión fiscal seguia siendo baja, y el Estado no confiscaba los recursos privados a través de los impuestos, a pesar de las frecuentes quejas de los contribuyentes españoles ${ }^{49}$.

Diezmo, y de los impuestos indirectos que gravaban las transacciones comerciales, particularmente las Alcabalas y los Portazgos; véase Fontana (1977) y Comin (1988a y 1991a).

46. Véase Serrano Sanz (1991). Los Aranceles si gravaban los inputs productivos, implicando en muchos casos protección efectiva negativa de la producción industrial; los intentos de Figuerola buscando un Arancel industrialista son la excepción, como señaló Costas Comesaña (1988).

17 Aunque en 1900 con la Contribución de Utilidades de Fernández Villaverde se consolidaron los impuestos sobre los salarios y sobre el capital - y en 1920 se gestó el embrión del impuesto sobre sociedades-, la Contribución de utilidades se nutria sobre todo de los rendimientos del Impuesto sobre los intereses de la Deuda. La mala administración impedia cobrarlos propiamente, con lo que esos factores de la producción ni siquiera soportaron la pequeña presion fiscal dictada en la legislación tributaria.

48 El problema radicaba en que aquel sistema fiscal decimonónico no instauró mecanismos para asegurar que ese ahorro se inviertiese efectivamente; los liberales suponian que la iniciativa privada lo invertiria automáticamente, según la Ley de Say.

$49 \mathrm{Y}$ menos aún si se tiene en cuenta que, debido al regresivo reparto de la carga tributaria, quienes habian de tomar las decisiones productivas y de inversión soportaban una presión fiscal inferior a la legalmente establecida. Por lo tanto, entre 1845 y 1935 los ingresos del Estado favo- 
Hay que tener presente, sin embargo, que si la ligera presión fiscal no reducía la oferta de los factores, los reducidos ingresos públicos lastraron la industrialización indirectamente, porque impidieron financiar un mayor esfuerzo inversor en infraestructuras y en educación, que hubiera promovido el progreso económico. Pero, de nuevo, hay que recordar que los políticos decimonónicos preferian mantener el viejo sistema tributario antes que reformarlo para aumentar la recaudación y mejorar la equidad tributaria ${ }^{50}$. En cualquier caso, los políticos hubieran podido recurrir a la emisión de Deuda pública para financiar los «gastos reproductivos», como recomendaba la ortodoxia financiera clásica: así se hizo, de hecho, para financiar los esfuerzos de fomento económico de los tiempos de la Unión Liberal y la Dictadura de Primo de Rivera 51. Pero, como se ha visto en la sección anterior, durante el siglo XIX y primera mitad del xx en España, los gastos en infraestructura, educación y sanidad no eran considerados imprescindibles por los políticos gobernantes; y menos si para financiarlos había que tocar los intereses económicos de las clases privilegiadas. En suma, los raquiticos ingresos tributarios no fueron una restricción presupuestaria exógena que limitase los gastos del Estado; al contrario la pobreza de la Hacienda es algo explicable por variables políticas e ideologías, pues los dirigentes del país optaron claramente por el conservadurismo fiscal y por la ineficacia política y administrativa; ese era el precio que habia que pagar para preservar el orden económico, político y social ${ }^{52}$.

recieron el crecimiento económico; desde luego, es dificil que pudieran lastrarlo. Los liberales sostenian que una baja presión fiscal favoreceria el crecimiento económico; el ajuste es defectuoso, pero en el grafico 10 se advierte que la relación entre la presión fiscal y el crecimiento económico, aunque débil, parece ser positiva.

so Se impusieron, en la práctica, los intereses de los terratenientes, industriales y comerciantes, que defendian un sistema tributario que permitiera defraudar o, al menos, eludir al fisco para no pagar siquiera los pocos impuestos que según ley les correspondia. Viendo el evidente coste político de la acción de incrementar los impuestos, los gobernantes de la Restauración, y de las dictaduras que siguieron, no percibian qué beneficios inmediatos y personales podrían cosechar de esa politica fiscal de desarrollo; véase Comin (1987). Es más, para aumentar los ingresos hubiera bastado con mejorar la gestion tributaria y acabar con el fraude fiscal, sin necesidad de efectuar una reforma tributaria, como señalaron Comin (1990) y Pro (1992). Para el cuadro tributario de la Restauración, véase Tedde (1984).

"Las emisiones para obras públicas contaban, empero, con la restricción práctica que hallaban los ministros de Hacienda en los altos volúmenes de Deuda ya existentes, que hipotecaban un alto porcentaje del gasto público. A la emisión de Deuda se recurria, por otro lado, cuando habia que pagar gastos ineludibles como eran los bélicos y los intereses de la Deuda.

52 Como tan contundentemente demostró Varela (1977) para la Restauración. Esto se aplica para el sistema politico; lo que no excluye que algunos ministros progresistas propusieran reformas en ese sentido, que se vieron anegadas en medio de la indiferencia nacional, y ahogadas por la hostilidad de la política. 


\section{GRAFICO 11}

Contribuciones indirectas (1850-1990)

(Porcentaje en los recursos no financieros)

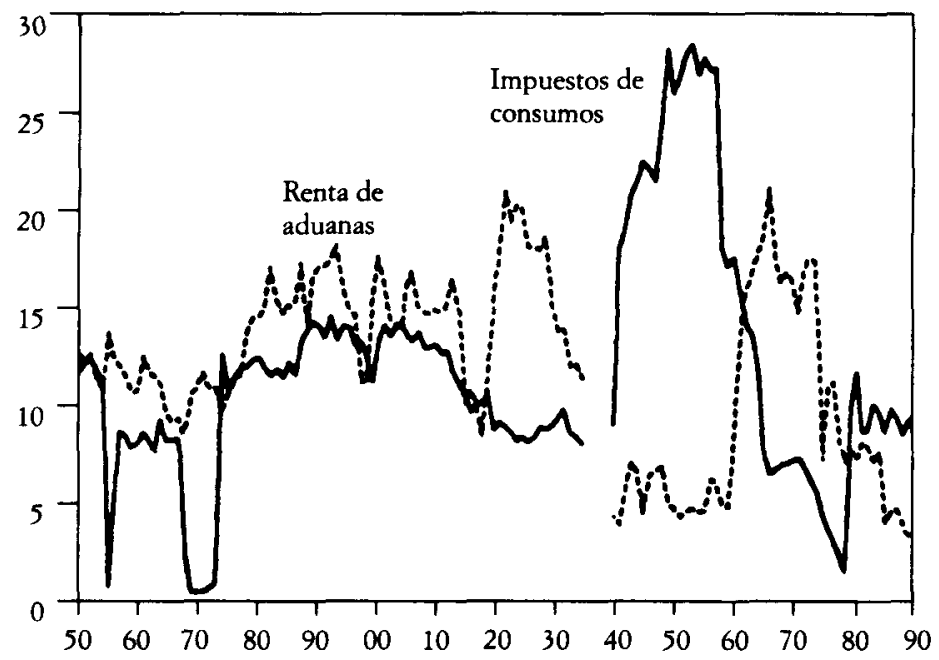

GRAFICO 12

Contribución de utilidades (1850-1990)

(Porcentaje en los recursos no financieros)

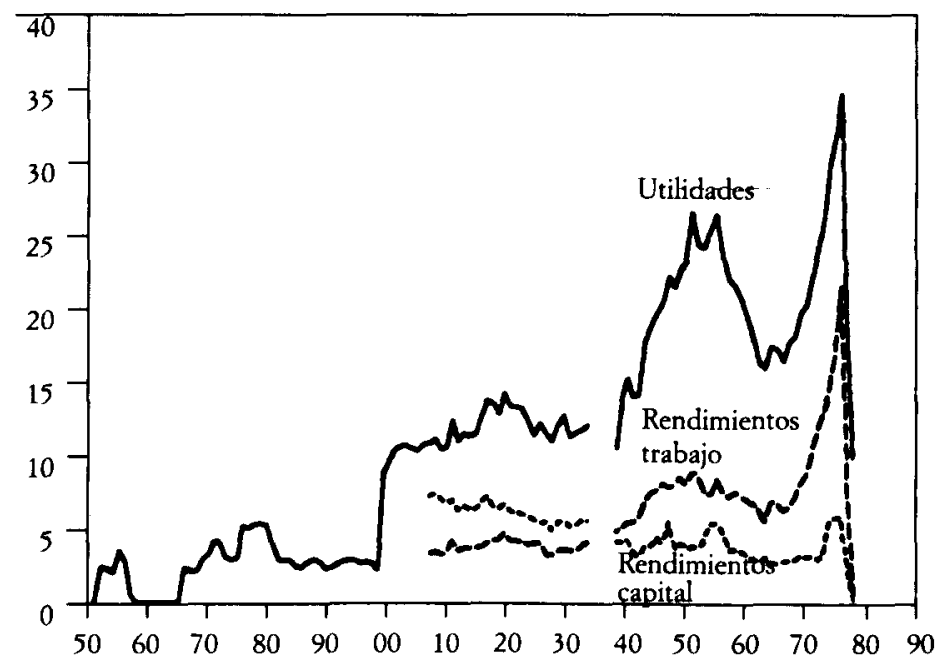


Durante el franquismo siguieron dominando los impuestos indirectos (gráfico 11). Pero tras la reforma fiscal de 1957 de Navarro Rubio, el papel del sistema fiscal frente al crecimiento económico cambió ligeramente: el gravamen sobre el trabajo comenzó a recaudar cifras mayores desde los años cincuenta, y la presión fiscal sobre los salarios se reforzó desde los sesenta; los rendimientos del capital siguieron tributando menos (gráfico 12), pero el Impuesto de sociedades aumentó su cuantía, lo que unido al aumento, desde 1967, de las cuotas empresariales a la Seguridad Social pudo obstruir la inversión y la creación de empleo, además de empeorar la competitividad de los productos españoles en el exterior. En cualquier caso, los tipos impositivos soportados por trabajadores y empresarios no eran tan altos como para reducir significativamente la oferta de trabajo y de capital. La situación cambió desde la reforma fiscal iniciada en 1977, pues la progresividad nominal del IRPF (y sobre todo desde 1983, tras la desaparición de las desgravaciones a las distintas fórmulas de ahorro) puede retraer el desarrollo económico ${ }^{53}$.

En definitiva, antes de 1977 la tributación no puso trabas insalvables a la industrialización; porque aunque los tipos impositivos pareciesen elevados, el amplio fraude los reducía en la práctica; además la evasión fiscal era mayor en las personas acaudaladas, en las rentas del capital y en las actividades profesionales. Por el contrario, tras las reforma tributaria iniciada 1977 el Impuesto sobre la renta puede desincentivar el ahorro privado tanto por la progresividad de sus tarifas como por la desaparición de los incentivos fiscales a la inversión 54 .

\section{LAS DIFICILES CONCLUSIONES}

En la experiencia histórica internacional, el análisis de la influencia del gasto público sobre el crecimiento económico se enfrenta a la indeterminación de los resultados de la investigación empírica 5 . Con todo, es incuestionable

"3. Véase Fuentes Quintana (1990).

54 Hay considerable polémica sobre si la fiscalidad retrae el ahorro; véanse González Páramo (1991) y Argimón y Roldán (1991).

"Por un lado, gran parte de los trabajos descansan en métodos precarios; Saunders (1986) criticó los estudios que no desagregan por categorias del gasto, que no teorizan sobre la posible relación entre ellos y el crecimiento, y que no controlan la acción de otros determinantes del crecimiento. Además, hay resultados para todos los gustos: a) con la variable explicativa retrasada, Friedland y Saunders (1985) encuentran que el aumento de la carga fiscal tiende a reducir el crecimiento económico, pero que un aumento de las transferencias tiende a mejorar la actividad económica; b) Ram (1986) estima que el nivel del gasto del gobierno tuvo un ligero efecto negativo sobre el crecimiento en los sesenta, y algo mayor en los setenta, pero que la tasa de crecimiento 
que ciertos gastos públicos incrementan la productividad de la economia; se trata de la inversión en infraestructuras, de los gastos en educación e investigación, que el mercado no acierta a suministrar, y de los gastos sociales, sanitarios y en redistribución que, al ofrecer seguridad a la mano de obra, mejoran su productividad. Estimaciones recientes resaltan, en efecto, que aunque el crecimiento económico es frenado por el consumo del Estado, los restantes gastos públicos tienen unos efectos positivos mayores; concretamente, las inversiones en infraestructuras, las transferencias sociales y los gastos en educación mejoran la productividad total de los factores ${ }^{56}$. Para España, por su parte, se ha demostrado que el aumento del gasto en infraestructuas de trans. portes y comunicaciones favoreció el crecimiento posterior a $1985^{57}$, y lo mismo podría decirse del mayor gasto en educación y en investigación; en cualquier caso, esos gastos públicos son aún claramente insuficientes ${ }^{58}$.

Si los resultados econométricos no son decisivos, tampoco podrán serlo las apreciaciones cualitativas aquí presentadas. En el campo de la Hacienda pública, como en otras parcelas históricas, España no ha sido muy diferente a otros paises europeos; la peculiaridad radica en que aquí los fenómenos se han presentado con cierto retraso. Ni siquiera los déficit crónicos en la Hacienda española de los siglos XIX y $\mathrm{xX}$ han sido algo castizo, pues el déficit presupuestario ha predominado en Europa en la época contemporánea 59; unos países se industrializan con déficit públicos, mientras que otros lo hacen con superávit. Y esto es así porque el saldo del Presupuesto de la Hacienda por sí solo explica pocas cosas; para ver sus efectos hay que analizar su dimensión, sus componentes y su financiación.

del consumo público tiene un impacto positivo en el crecimiento; c) Weede (1986) señala la existencia de un fuerte impacto negativo del gasto público, particularmente de las transferencias de la seguridad social.

${ }_{56}$ Castles y Dowrick (1986, pp. 179-197) encuentran que ni los gastos militares ni el tamano del déficit público tienen efectos significativos a medio plazo sobre el crecimiento del PIB y la productividad de los factores.

57 Véase Argimón, González-Páramo et al. (1993), que sostienen que la inversión pública en infraestructuras tuvo un efecto positivo sobre la productividad del sector privado; y que el efecto expulsión de la inversión pública sobre la privada es de pequeña magnitud en el caso español.

${ }_{58}$ El trabajo de Andrés, Domenech y Molinas (1993) concluye que el modelo de Solow que incorpora el capital humano explica razonablemente bien la convergencia entre los paises de OECD entre 1960 y 1990. Aunque el crecimiento pudo ser retardardo por la considerable expansión del gasto público corriente, que explica casi la cuarta parte de la desaceleración del crecimiento del PIB entre los periodos 1960-1974 y 1975-1991, según Raymond (1992).

59 Es más, la principal peculiaridad española sucedió durante los años cincuenta y sesenta cuando se planteaban en Europa politicas fiscales keynesianas con amplios déficit, mientras que en España el Presupuesto se saldaba equilibrado por mantenerse la ortodoxia financiera clásica; véanse Comin (1992) y Gunther (1980). 
En efecto, tanto o más que del déficit presupuestario, los efectos sobre el crecimiento dependen del tipo de gastos que se financien con las emisiones de la Deuda; los gastos de inversión fomentan el crecimiento, mientras que los de consumo no suelen hacerlo. Asimismo, también tiene relevancia la amplitud de los déficit, su duración temporal y la forma de financiación; si los déficit son voluminosos y duraderos y se financiaban con Deuda, su efecto expansivo será notable, pero entonces sus cargas financieras acabarán engullendo una porción considerable de los gastos públicos futuros, colapsando el gasto en otras funciones que favorecen la industrialización. En España, la mejor prueba del papel secundario de la política presupuestaria está en el proceso industrializador de los años sesenta; fue precedido por una liberalización exterior y una desregulación interior, pero no fue acompañado por ningún cambio significativo en la política de ingresos públicos; la dimensión y estructura del gasto público se transformaron algo, pero esto fue un efecto del progreso económico, más que una causa ${ }^{60}$.

Desde una óptica keynesiana, el Estado no se esforzó a través del Presupuesto para industrializar el pais, porque no ejecutó las inversiones capaces de arrastrar a la industria. Ni siquiera desde la perspectiva clásica el Estado español se comportó ortodoxamente; es cierto que instauró un sistema fiscal favorable al crecimiento económico, y que dejó todo el protagonismo en manos de la iniciativa privada; sin embargo, el cuadro tributario no fue suficiente, no se equilibraron los presupuestos, y los políticos no recurrieron a la emisión de Deuda pública para financiar proyectos de inversión que dotasen al pais de la infraestructura básica.

Aunque no se le haya prestado tanta atención, la estructura tributaria también tiene que ver con el crecimiento económico. Los impuestos en España no han obstaculizado el crecimiento económico; pero la ausencia de una reforma tributaria empobreció al Estado, que no pudo suministrar los bienes y servicios minimos que exige la industrialización. La pervivencia de la ideologia prekeynesiana - y los altos volúmenes de Deuda derivados de atrasos y operaciones bélicas- impidió que los ministros se atreviesen a emitir grandes partidas de Deuda para financiar los proyectos de gastos extraordinarios; y cuando se decidieron a pedirlos, las Cortes se los negaron. El Estado dejó el protagonismo de la industrialización en manos de la iniciativa privada, que se mostró incapaz de conseguirla, en parte por la excesiva regulación económica.

60 Véase Comín (1988b). Ese desarrollo económico de los sesenta obedeció al impulso de la iniciativa privada, ayudada financiera y tecnológicamente desde el sector exterior. Si el Sector Público hizo algo durante los años sesenta fue, seguramente, obstruir aquel crecimiento; véase Fuentes Quintana (1989) y Segura (1992). 
Como señalaba al principio, la relación entre el Estado y el crecimiento es más compleja, por el hecho de que la acción económica del Estado puede ejecutarse por vias extrapresupuestarias. En un estudio reciente concluía que los obstáculos al crecimiento económico en España fueron: 1) la desconfianza de politicos, empresarios y trabajadores hacia el mecanismo de mercado y la consiguiente inclinación a la intervención estatal, que explica la insuficiente y timida liberalización de algunos mercados internos (financiero y trabajo), así como la excesiva regulación de otros, que acentúa la tendencia a la inflación ${ }^{61}$; 2) la tradicional deficiencia en la oferta pública de infraestructuras de transporte y comunicaciones, y los siempre insuficientes, y mal distribuidos, gastos públicos en educación e investigación; 3) el persistente déficit de las Administraciones públicas, en unas fases más grave que en otras, impidió hasta muy recientemente la existencia de una política monetaria autónoma, pues su fin principal era financiar aquellos déficit presupuestarios ${ }^{62}$; 4) la incapacidad histórica de la economía española para adquirir mayor autonomía de las importaciones del exterior, tanto bienes de equipo y tecnología, como productos semielaborados y energéticos, que explica el desequilibrio comercial exterior; 5) el insuficiente ahorro nacional que ha obligado a depender en exceso de la inversión exterior; 6) finalmente, la reducida dimensión del mercado interior es el origen de la ausencia de corporaciones multinacionales españolas, que impide acceder a los mercados internacionales y aprovechar las nuevas tecnologias ${ }^{63}$.

Si éstos son los obstáculos al crecimiento, la parte que le corresponde al Estado en esa responsabilidad del atraso económico español no es, por tanto, pequeña. No obstante, los efectos más desfavorables no procedieron de la política presupuestaria.

\section{BIBLIOGRAFIA}

Almenar, S. (1983): «Keynesianos en España, 1936-1953», Debats, núm. 6, pp. 103-108. ANDREs, Javier; DoméneCH, Rafael, y Molinas, César (1993): Growth, Convergence and Macroeconomic performance in OECD countries: A closer look, Ministerio de Economia y Hacienda, Documento de Trabajo.

${ }_{61}$ Véase Comin (1993b). Esta intervención estatal, integral y arbitraria, tiene su explicación en la esclerosis institucional, surgida de las presiones de los grupos de presión, empresariales y sindicales, y en que las autoridades españolas han carecido, hasta la entrada en la Comunidad Europea, de los compromisos internacionales que les permitieran evadirlas.

62 Más recientemente, la política fiscal ha dejado a la autoridad monetaria que persiga en solitario la estabilidad de los precios y el mantenimiento del cambio de la peseta, ya que no se corrigió el déficit de las Administraciones públicas.

${ }^{3}$ Como ha señalado Segura (1992). 
Antol.tn, F. (1991): «Las empresas de servicios públicos municipales», en Comin, F., y P. Martin ACEÑa (eds.): Historia de la empresa pública en España, Madrid, Espasa Calpe, pp. 283-329.

Arana, I. (1988): La Liga Vizcaína de Productores y la política económica de la Restauración, Bilbao, Caja de Ahorros Vizcaina.

Argimon, I., J. M. GonzAlez-PARAmo et al. (1993): La incidencia del gasto público en la productividad de la economía española, inédito, Servicio de Estudios, Banco de España.

ARGIMÓN, I., y J. M. ROLDÁN (1991): Aborro, inversión y movilidad internacional del capital en los paises de la CEE, Documento de Trabajo, 9110, Servicio de Estudios, Banco de España.

Bajo, O., y S. Sosvilla (1992): Does Public Capital Affect Private Sector Performance? An Analysis of the Spanish Case 1964-1988, UNED, Facultad de Económicas, Documento de Trabajo, 9208.

BANDRES, E. (1990a): Los efectos de los gastos sociales sobre la distribución de la renta en España, Madrid, Instituto de Estudios Fiscales, Monografía núm. 92.

- (1990b): «Equipamientos e infraestructuras: un costoso legado de la transición», en J. L. GaRcia Delgado (dir.): Economía española de la transición y la democracia, Madrid, Centro de Investigaciones Sociológicas, pp. 273-305.

CABrera, M. (1983): La patronal ante la II República. Organizaciones y estrategia, 1931-1936, Madrid, Siglo XXI.

CARR, R. (1980): Modern Spain, 1875-1980, Oxford, OUP.

Carreras, A. (1990): Industrialización española: estudios de historia cuantitativa, Madrid, Espasa Calpe.

- (1992): «La producción industrial en el muy largo plazo. Una comparación entre España e Italia de 1861 a 1980m, en L. PRAdos DE LA Escosura y V. ZAMAGni (eds.): El desarrollo económico en la Europa del Sur: España e Italia en perspectiva bistórica, Madrid, Alianza, pp. 173-209.

Castellano, F. (1975): «Evolución de la estructura de los servicios públicos en España», Hacienda Pública Española, núm. 36, pp. 35-65.

CASTLES, F. G., y Dowrick, S. (1990): «The Impact of Government Spending Levels on Medium-Term Economic Growth in the OECD, 1960-1985», Joumal of Theoretical Politics, vol. 2, num. 2, pp. 173.204.

CATALAN, Jordi (1992): «Reconstrucción, política económica y desarrollo industrial: tres economias del sur de Europa, 1944-1953», en Leandro Prados de la Escosura y Vera Zamagni (eds.): El desarrollo económico en la Europa del Sur: España e Italia en perspectiva bistórica, Madrid, Alianza Editorial, pp. 359-395.

Colclough, C., y Manor, J. (eds.) (1991): States or Markets? Neoliberalism and the Development Policy Debate, Oxford, Clarendon Press.

Comin, F. (1985): «La evolución del gasto del Estado en España, 1901-1972: contrastación de dos teorias», en P. Martin Acena y L. PRados DE La Escosura (eds.): La nueva bistoria económica en España, Madrid, Tecnos.

(1986): «El Presupuesto del Estado tras la Guerra Civil: dos pasos atrás», Economistas, núm. 21, pp. 24-32.

(1987a): «La economía española en el período de entreguerras», en J. NADAL, A. CARRERAS y C. SUDRIA (comps.): La economía española en el siglo XX. Una perspectiva bistórica, Barcelona, Ariel, pp. 105-149. 
(1987b): «Perfil histórico de la Deuda pública en España», Papeles de Economía Española, núm. 33, pp. 86-119.

- (1987c): «Las transformaciones tributarias en la España de los siglos XIX y XX», Hacienda Pública Española, núms. 108-109, pp. 441-467.

- (1988a): Hacienda y economía en la España contemporánea, Madrid, Instituto de Estudios Fiscales.

- (1988b): «Evolución histórica del gasto público», Papeles de Economía Española, núm. 37, pp. 78-99.

- (1990): Las cuentas de la Hacienda preliberal en España, (1801-1855), Madrid, Banco de España.

— (1991): «Raices históricas del fraude fiscal en España», Hacienda Pública Española, núm. 1, pp. 191-206.

- (1992): «La reconstrucción económica de la Europa occidental. Comentario», en M. Cabrera, S. Julia y P. Martin Aceñ (eds.): Europa. 1945-1990, Madrid, Fundación Pablo Iglesias, pp. 37-42.

- (1993a): Estadísticas del sector público en España (1800-1992), inédito.

- (1993b): Estado y Crecimiento económico en España: lecciones de la Historia, en vías de publicación por la Real Academia de Ciencias Morales y Políticas.

- y P. MARTin ACEÑa (dirs.) (1990): Historia de la empresa pública en España, Madrid, Espasa Calpe.

Comisión del Patrón Oro (1929): «Dictamen de la Comisión nombrada por Real Orden de 9 de junio de 1929 para el estudio de la implantación del patrón oro», reproducido en Información Comercial Española, núm. 318, pp. 51-83.

Corrales, A., y D. Taguas (1991): «Series macroeconómicas para el periodo 1954-1989: un intento de homogeneización», en C. Molinas et al. (eds.): La economía española. Una perspectiva macroecónomica, Madrid, Instituto de Estudios Fiscales.

Costas Comesaña, A. (1988): Apogeo del liberalismo en "La Gloriosa». La reforma económica en el Sexenio liberal (1868-1874), Madrid, Siglo XXI.

- (1992): «Gasto público y regulación económica en España», en Economía española, cultura y Sociedad. Homenaje a Juan Velarde, Madrid, Eudema, vol. I, pp. 417-431.

CRafTs, N. (1992): «Productivity Growth Reconsidered», Economic Policy, núm. 15, pp. 388-426.

Davis, L. E., y Huttenback, R. A. (1988): Mammon and the Pursuit of Empire. The Economics of British Imperialism, Cambridge University Press.

Del Moral Ruiz, J. (1979): Gasto Público y expansión económica en España, 1845-1865, Madrid, Instituto de Estudios Fiscales.

Del Rey Regullo, Fernando (1992): Propietarios y patronos. La política de las organizaciones económicas en la España de la Restauración (1914-1923), Madrid, Ministerio de Trabajo y Seguridad Social.

EsTAPE, F. (1971): La reforma tributaria de 1845, Madrid, Instituto de Estudios Fiscales.

Florensa, S. (1981): «Economia y política en la II República. Una nota de sintesis», $A r-$ bor, núms. 426-427, pp. 111-124.

FontanA, J. (1971): La quiebra de la monarquía absoluta, Barcelona, Ariel.

- (1973): Hacienda y Estado en la crisis final del Antiguo Régimen español, 1823-1833, Madrid, Instituto de Estudios Fiscales.

- (1977): La Revolución Liberal (Política y Hacienda): 1833-1845, Madrid, Instituto de Estudios Fiscales. 
— (1980): La Hacienda en la Historia de España (1700-1931), Madrid, Instituto de Estudios Fiscales.

Fraile, P. (1985): «El fracaso de la revolución industrial en España: un modelo cerrado de industrialización», Información Comercial Española, núm. 623, pp. 97-104.

(1991): Industrialización y grupos de presión, Madrid, Alianza.

Friendland, R., y J. Sanders (1985): «The Public Economy and Economic Growth in Western Market Economies», American Sociological Review, 50, pp. 421-437.

Fuentes Quintana, E. (1989): «Tres decenios de la economía española en perspectiva», en J. L. Garcta Delgado (dir.): España. Economia, Madrid, Espasa Calpe, pp. 1-75.

- (1990): Las reformas tributarias en España. Teoría, historia y propuestas, Barcelona, Critica.

- (1991): El papel del sector público en tres economistas asturianos, inédito.

- (1993): El profesor Flores de Lemus y los problemas actuales de la economía española Discurso pronunciado con motivo de la investidura como Doctor Honoris Causa por la Unversidad de Sevilla.

Garcia Delgado, J. L. (1984): «La industrialización española en el primer tercio del siglo XX», en J. M. JOVER (ed.): Los comienzos del siglo XX. La población, la economía, la sociedad (1898-1931), Madrid, Espasa-Calpe, pp. 3-171.

(1987): «La industrialización y el desarrollo económico de España durante el franquismo», en Nadal, J.; Carreras, A., y SudriÀ, C. (comps): La economía española en el siglo XX. Una perspectiva bistórica, Barcelona, Ariel, pp. 164-189.

- y J. M. Serrano SANZ (1991): «Economia», en Manuel Tuñon de Lara (dir.): Transición y Democracia (1973-1985), vol. 10.2, Historia de España, Barcelona, Labor, pp. 189-311.

Gomez Mendoza, A. (1982): Ferrocarriles y cambio económico en España, 1855-1913, Madrid, Alianza.

- (1989): Ferrocarril, industria y mercado en la modernización de España, Madrid, EspasaCalpe.

Gonzalez, M. J. (1979): La Economía Política del Franquismo (1940-1970). Dirigismo, mercado y planificación, Madrid, Tecnos.

Gonzalez-PÁramo, J. M. (1991): «Fiscalidad personal y composición del Ahorro en España», Papeles de Economia Española, núm. 48.

Gonzalo, L. (1981): El Tesoro Público y la Caja General de Depósitos, 1852-1868, Madrid, Instituto de Estudios Fiscales.

Gunther, R. (1980): Public Policiy in a No-Party State. Spanish Planning and Budgeting in the Twilight of the Franquist Era, Berkeley, University of California Press.

Hernandez Andreu, J. (1980): Depresión económica en España, 1925-1934, Madrid, Instituto de Estudios Fiscales.

Instituto Nacional de Estadistica (1992): Contabilidad Nacional de España. Serie enlazada 1964-1991. Base 1986, Madrid.

Jover, J. M. (1981): «La época de la Restauración. Panorama Politico-social, 1875-1902», en M. TUNON DE LARA (ed.) (1981): Revolución burguesa, oligarquia y constitucionalismo (1834-1923), Barcelona, Labor, pp. 271.406.

Llombart, V. (1992): Campomanes, economista y político de Carlos III, Madrid, Alianza.

LluCH, E. (1988): «Fue la Hacienda Pública española proclive al proteccionismo?», Economistas, núm. 34, pp. 40-53. 
Maluquer DE Motes, J. (1986): «Aislamiento y diversificación estructural, 1898-1921», en J. Nadal, Albert CaRreras, Carles Sudria (comp.): La economía española en el siglo XX. Una perspectiva histórica, Barcelona, Ariel, pp. 62-103.

Martin Aceña, P. (1981): «España y el Patrón-Oro, 1880-1913», Hacienda Pública Española, núm. 69, pp. 267-302.

- (1984): La política monetaria en España, 1919-1935, Madrid, Instituto de Estudios Fiscales.

- (1985a): «Desarrollo y modernización del sistema financiero, 1844-1935», en N. SÁNCHEZ-AlboRNOZ (ed.) (1985): La modernización económica de España (1830-1930), Madrid, Alianza, pp. 121-146.

- (1985b): La cantidad de dinero en España, 1900-1935, Madrid, Banco de España.

- y ComfN, F. (1991): INI. 50 años de industrialización en España, Madrid, Espasa Calpe.

Martin Niño, J. (1972): La Hacienda española y la Revolución de 1868, Madrid, Instituto de Estudios Fiscales.

Melguizo, A. (1979): «El presupuesto de Calvo Sotelon, Cuadernos Económicos de ICE, núm. 10, pp. 301-462.

Milward, Alan S. (1992): «The Economic Reconstruction of Western Europe», en M. Cabrera, S. Juliá, P. Martin Aceña (eds.): Europa, 1945-1990. Fundación Pablo Iglesias, pp. 19-36.

Molinas, C., y Prados de la Escosura, L. (1989): «Was Spain Diferent? Spanish Historical Backwardness Revisited», Explotarions in Economic History, vol. 26, num. 4, pp. 385-402.

Mora, A. (1984): «El concepto de crowding out y su análisis empirico», Hacienda Pública Española, núm. 88, pp. 189-194.

NADAL, J. (1975): El fracaso de la Revolución industrial en España, 1814-1913, Barcelona, Ariel.

Navarro Rubio, Mariano (1991): Mis memorias, Barcelona, Plaza y Janés.

NúNEZ, C. E. (1990): «Literacy and Economic Growth in Spain, 1860-1977», en G. ToRTELLA (ed.): Education and Economic Development since the Industrial Revolution, Valencia, Generalitat Valenciana, pp. 125-151.

- (1992): La fuente de la riqueza. Educación y desarrollo económico en la España contemporánea, Madrid, Alianza.

O'Brien, P. (1989): «Public Finance in the Wars with France, 1793-1815", en H. T. Dickinson (ed.): Britain and the French Revolution, 1789-1815, London, MacMillan, pp. 165-188.

O'BriEn, P. K. (1988): «The Political Economy of British Taxation, 1660-1815», Economic History Review, núm. 1, pp. 1-32.

Palafox, J. (1992): Atraso Económico y democracia. La Segunda República y la economía española (1892-1936), Barcelona, Crítica.

Prados de la Escosura, L. (1988): De imperio a nación. Crecimiento y atraso económico en España (1780-1930), Madrid, Alianza.

(1992): «Crecimiento, atraso y convergencia en España e Italia, introducción», en L. Prados DE la Escosura y V. ZamaGni (eds.): El desarrollo económico en la Europa del Sur: España eltalia en perspectiva bistórica, Madrid, Alianza, pp. 27-55.

(1993a): Spain's Gross Domestic Product, 1850-1990. A New Series, Dirección General de Planificación, Ministerio de Economía y Hacienda. 
- (1993b): «Long-run Economic Growth in Spain since 1800: An International Perspective», en A. SzIRmai, B. van ARK y D. Pilat (eds.): Explaining Economic Growth. Essays in Honour of Angus Maddison, Amsterdam, North Holland, pp. 267. 284.

- y S. Amaral (eds.) (1993): La independencia americana: consecuencias económicas, Madrid, Alianza.

Pro, Juan (1992): Estado, geometría y propiedad. Los orígenes del Catastro en España (17151941), Madrid, Ministerio de Economia y Hacienda.

Ram, R. (1986): «Government Size and Economic Growth: A New Framework and Some Evidence from Cross Section and Time-Series Datas, American Economic Review, núm. 1, pp. 191-203.

Raymond, J. L. (1992): «Gasto público y crecimiento económico. Un análisis de los efectos del tamaño del sector público en España y en la Europa comunitaria», $\mathrm{Pa}$ peles de Economía Española, núms. 52-53, pp. 180-198.

_ (1993): «Acortamiento de distancias y convergencia en los países de la Europa de los doce», Documento inédito, Fundación FIES.

SABATÉ, M. (1992): La reforma arancelaria de 1906: la protección legitimada, Tesis doctoral inédita, Universidad de Zaragoza.

SARDA, J. (1948): La política monetaria y las fluctuaciones de la economía española en el siglo XIX (reedición por Ariel, Barcelona, 1970).

SAUNDERS, P. (1986): «What Can We Learn from International Comparisons of Public Sector Size and Economic Performance», European Sociological Review, vol. 2, núm. 1, pp. 52-60.

SChremmer, E. (1989): «Taxation and Public Finance: Britain, France and Germany», en The Cambridge Economic History of Europe, vol. VIII, The Industrial Economies: The Development of Economic and Social Policies, Cambridge University Press, pp. 315. 494.

SEGURA, J. (1992): La industria española y la competitividad, Madrid, Espasa Calpe.

SERRANo SANZ, J. M. (1987a): El viraje proteccionista en la Restauración. La política comercial española, 1875-1895, Madrid, Siglo XXI.

- (1987b): «La politica comercial ante la crisis del veintinueve: el primer bienio republicanom, en J. L. Garcia Delgado (ed.): La II República española. El Primer bienio, Madrid, Siglo XXI, pp. 135-152.

- (1986): «La politica arancelaria española al término de la Primera Guerra Mundial: protección, Arancel Cambó y tratados comerciales», en J. L. Garcta Delgado (ed.) (1986): La crisis de la Restauración. España entre la Primera Guerra Mundial y la Segunda República, Madrid, Siglo XXI, pp. 199-223.

(1992): «La apertura exterior de la economia española en perspectiva (1901. 1980)», en Economía española, cultura y Sociedad. Homenaje a Juan Velarde, Madrid, Eudema, vol. I, pp. 433-451.

- (1989): «El proteccionismo y el desarrollo económico en la Restauración. Reflexiones para un debate», Revista de Historia Económica, núm. 1, pp. 133-156.

(1991): «La renta de Aduanas en España (1849-1935)», Hacienda Pública Española, núm. 1, pp. 107-120.

- y A. Costas Comesaña (1990): «La reforma institucional de la Economia de la Transición», en J. L. Garcia Delgado (dir.): Transición y democracia en España, Madrid, CIS. 
Solé Villalonga, G. (1967): La reforma fiscal de Villaverde, 1899-1900, Madrid, Editorial de Derecho Financiero.

(1964): La Deuda pública en España y el mercado de capitales, Madrid, Instituto de Estudios Fiscales.

SUDRIÀ, C. (1990): «Los beneficios de España durante la gran guerra. Una aproximación a la balanza de pagos española, 1914-1920», Revista de Historia Económica, núm. 2, pp. 363-396.

TedDe DE LoRCA, P. (1981): «El gasto público en España (1875-1906). Un análisis comparativo con las economias europeas», Hacienda Pública Española, núm. 69, pp. 236266.

- (1985): «El sector financiero y el fracaso de la revolución industrial, 1814-1913», Información Comercial Española, núm. 623, pp. 39-46.

- (1984): «Aproximación al cuadro tributario de la Restauración», Hacienda Pública Española, núm. 87, pp. 323-338.

— (1987): «Crisis del Estado y Deuda Pública a comienzos del siglo XIX», Hacienda Pública Española, Núms. 108-109, pp. 169-197.

Tortella, G. (1981): «La economía española, 1830-1900», en M. TuNón DE Lara (ed.): Revolución burguesa, oligarquía y constitucionalismo (1834-1923), Barcelona, Labor, pp. 11-167.

- (1990): «Education and Economic Development Since the Industrial Revolution: A Summary Report (The Less Developed Countries)», en G. TorTella (ed.): Education and Economic Development since the Industrial Revolution, Valencia, Inst. Alfonso el Magnánimo.

(1992): «La historia económica de España en el siglo Xx: un ensayo comparativo con los casos de Italia y Portugal», en L. PRAdos DE LA Escosura y V. ZamaGni (eds.): El desarrollo económico de la Europa del Sur: España e Italia en perspectiva bistórica, Madrid, Alianza, pp. 56-80.

VACCARO, R. (1980): «Industrialization in Spain and Italy (1860-1914)», The Joumal of European Economic History, núm. 3, pp. 709-751.

Varela Ortega, J. (1977): Los amigos políticos. Partidos, elecciones y caciquismo en la Restauración (1875-1900), Madrid, Alianza.

VelaRde, J. (1968): Política Económica de la Dictadura, Madrid, Guadiana.

- (1990): Economistas españoles contemporáneos: primeros maestros, Madrid, Espasa Calpe.

WEEDE, E. (1986): «Catch-up, Distributional Coalitions and Government as Determinants of Economic Growth or Decline in Industrialised Democraciesm, British Journal of Sociology, 32, núm. 2, pp. 194-200.

Zamagni, Vera (1992): «La expansión económica europea», en M. Cabrera, S. Juliá y P. Martin ACENA (eds.): Europa, 1945-1990, Madrid, Fundación Pablo Iglesias, pp. 103-122. 